\title{
Oxaliplatin-Induced Neuropathy in Colorectal Cancer
}

\author{
Andrew Weickhardt, Keith Wells, and Wells Messersmith \\ Division of Medical Oncology, University of Colorado Cancer Center, Aurora, CO 80045, USA \\ Correspondence should be addressed to Andrew Weickhardt, andrewweickhardt@gmail.com
}

Received 2 September 2011; Accepted 24 October 2011

Academic Editor: Andrea Bonetti

Copyright ( 12011 Andrew Weickhardt et al. This is an open access article distributed under the Creative Commons Attribution License, which permits unrestricted use, distribution, and reproduction in any medium, provided the original work is properly cited.

\begin{abstract}
Oxaliplatin use in palliative and adjuvant treatment of colon cancer is frequently limited by cumulative neurotoxicity, leading to reduced quality of life and decreased dose. The mechanism of this neurotoxicity is unclear, but may relate to neuronal voltagegated sodium channels involving calcium chelation by a metabolite of the drug. Various preventative measures have been tested to reduce the incidence of neurotoxicity, including calcium and magnesium infusions, dose interruption of the drug, and prophylactic neuromodulatory agents. Despite the promising efficacy of these measures, they are not universally accepted. Less is known about the best way to treat established neurotoxicity, which is permanent in some patients, although venlafaxine has shown promise in small clinical trials. This paper analyzes the extent, cause and risk factors for neuropathy, and the potential preventative and therapeutic treatments for oxaliplatin-induced neuropathy.
\end{abstract}

\section{Introduction}

Oxaliplatin is a 3rd-generation platinum-based chemotherapeutic, possessing the 1,2 diaminocyclohexane-containing carrier ligand, useful in treating advanced colorectal cancer. It is often used in combination regimens with 5-flourouracil [1], capecitabine [2], or 5-flourouracil/irinotecan [3] for the treatment of colorectal cancer. Oxaliplatin has also been studied in clinical trials for the treatment of other cancers but has found the most success in gastrointestinal neoplasms including gastric, esophageal, and pancreatic cancers [4]. Platinum-based chemotherapeutics have effect via cell phase nonspecific mechanisms causing the formation of cross-linking DNA adducts, leading to strand breaks and inhibition of DNA replication [5].

Oxaliplatin produces common side effects of cytopenias, peripheral neuropathy, diarrhea, and nausea [4]. Oxaliplatin-induced neurotoxicity (OXIN) is a recognized dose-limiting complication [6]. This paper analyzes the extent, cause and risk factors for neuropathy, and the potential preventative and therapeutic treatments for OXIN.

\section{Extent of Problem}

OXIN demonstrates two clinically significant types: acute and chronic. Neither type has its mechanism of action fully elucidated. Acute OXIN usually begins with paresthesias and dysesthesias of the hands and feet, but may include the mouth or throat [7]. Its onset may begin during the initial infusion or up to 1-2 days following the administered dose and is often triggered by cold. Typically, the symptoms will resolve spontaneously within days, but often return upon subsequent oxaliplatin administration. It is associated with additional symptoms of muscular hyperactivity including jaw tightness, cramps, and fasciculations [8]. The proposed mechanism of action of acute OXIN includes altering the current of voltage-gated $\mathrm{Na}(+)$ channels in response to oxalate, a metabolic by-product of oxaliplatin $[9,10]$. In addition, oxalate may interact indirectly with the voltage-gated $\mathrm{Na}(+)$ channels through chelation of calcium $(\mathrm{Ca})$ and magnesium $(\mathrm{Mg})[11]$.

Chronic OXIN, in contrast, is thought to be caused by a dose-dependent accumulation of platinum compounds in the dorsal root ganglia, causing neuronal atrophy and apoptosis. It is primarily a sensory neuropathy affecting the extremities and develops based upon the total cumulative dose of oxaliplatin [12].

There is a wide discrepancy in the literature on how to measure and grade OXIN. The Common Terminology Criteria for Adverse Events (CTCAE) is often used by clinicians to score and monitor OXIN. The grading of peripheral 
TABLE 1: Common terminology criteria for adverse events version 4.03.

\begin{tabular}{|c|c|c|c|c|c|}
\hline Adverse event & Grade 1 & Grade 2 & Grade 3 & Grade 4 & Grade 5 \\
\hline Dysesthesia & Mild sensory alteration & $\begin{array}{l}\text { Moderate sensory } \\
\text { alteration; limiting } \\
\text { instrumental ADL }\end{array}$ & $\begin{array}{l}\text { Severe sensory alteration; } \\
\text { limiting self-care ADL }\end{array}$ & - & - \\
\hline Paresthesia & Mild symptoms & $\begin{array}{l}\text { Moderate symptoms; } \\
\text { limiting instrumental } \\
\text { ADL }\end{array}$ & $\begin{array}{l}\text { Severe symptoms; } \\
\text { limiting self care ADL }\end{array}$ & - & - \\
\hline $\begin{array}{l}\text { Peripheral } \\
\text { sensory } \\
\text { neuropathy }\end{array}$ & $\begin{array}{l}\text { Asymptomatic; loss of } \\
\text { deep tendon reflexes or } \\
\text { paresthesia }\end{array}$ & $\begin{array}{l}\text { Moderate symptoms; } \\
\text { limiting instrumental } \\
\text { ADL }\end{array}$ & $\begin{array}{l}\text { Severe symptoms; } \\
\text { limiting self care ADL }\end{array}$ & $\begin{array}{l}\text { Life-threatening } \\
\text { consequences; urgent } \\
\text { intervention indicated }\end{array}$ & Death \\
\hline $\begin{array}{l}\text { Peripheral } \\
\text { motor } \\
\text { neuropathy }\end{array}$ & $\begin{array}{l}\text { Asymptomatic; clinical } \\
\text { or diagnostic } \\
\text { observations only; } \\
\text { intervention not } \\
\text { indicated }\end{array}$ & $\begin{array}{l}\text { Moderate symptoms; } \\
\text { limiting instrumental } \\
\text { ADL }\end{array}$ & $\begin{array}{l}\text { Severe symptoms; } \\
\text { limiting self care ADL; } \\
\text { assistive device indicated }\end{array}$ & $\begin{array}{l}\text { Life-threatening } \\
\text { consequences; urgent } \\
\text { intervention indicated }\end{array}$ & Death \\
\hline
\end{tabular}

neuropathy from the CTCAE version 4.0 [13] is shown in Table 1. Other rating systems include the Total Neuropathy Score (TNS) [14], the Eastern Cooperative Oncology Group (ECOG) toxicity criteria, the oxaliplatin-specific scale [12], and criteria from individual studies or the World Health Organization [8]. Of these systems, none have been validated for oxaliplatin toxicity scoring. The CTCAE and the ECOG criteria have been compared to the TNS with reasonable validity for all chemotherapeutics [15]. Most clinical trials studying oxaliplatin use the CTCAE or the WHO criteria $[2,16$, 17].

\section{Incidence of Oxaliplatin-Induced Neuropathy}

Grade 2 or worse neuropathy occurs in approximately $40-50 \%$ of patients receiving oxaliplatin, with grade 3 neuropathy occurring in $10-20 \%$ of patients $[1,18-20]$. The majority of patients have improvement of their symptoms, but there is still a significant proportion of patients left with some symptoms more than 2 years after completing therapy $[1,20,21]$. In the MOSAIC trial, $44 \%$ of patients had grade 2 or grade 3 neurotoxicity at the end of treatment, $6 \%$ one year after therapy, and $4 \%$ after 18 months [1]. In a European trial of oxaliplatin, $26 \%$ of patients with grade 3 neurotoxicity had persistent symptoms after a median followup of 28 months [20]. More than $10 \%$ of patients in the NSABP C-07 trial who received oxaliplatin had persistent neurological symptoms 2 years after completing therapy [21]. In a small, 25-patient prospective study specifically evaluating the development of OXIN, $56 \%$ of patients developed grade $1-2$ OXIN and $8 \%$ developed grade 3 OXIN based on a modified TNS scoring [22]. An Australian prospective study of OXIN reported that neuropathy of any grade persisted in 79\% of patients, and grade 3 neuropathy persisted in $12 \%$ of patients after a median followup of 29 months [23].

3.1. Risk Factors. Preexistent symptomatic peripheral neuropathy has served as exclusion criteria from trials of oxaliplatin, and data on exacerbation of underlying neurotoxicity by oxaliplatin is limited. However, diabetes mellitus, which carries a high susceptibility of peripheral sensory neuropathy, does not appear to be associated with increased risk of developing OXIN [24]. Age also has not been shown to be a risk factor for the development of OXIN [25]. It has been hypothesized that genetic differences in the glutathione transferase pathway may lead to higher rates of neurotoxicity, perhaps due to a decreased ability to respond to oxaliplatin-induced oxidative stress [26-28]. However there is conflicting evidence whether ${ }^{105} \mathrm{Val}$ polymorphisms of glutathione Stransferase (GSTP1) leads to higher rates of OXIN $[29,30]$ and there are currently no clinical applications of this basic scientific work. Integrin beta-3 polymorphisms have been shown to be unrelated to the development of OXIN, but may be related to its severity [31]. In a genome-wide analysis of 96 colon cancer patients, a group from South Korea showed a possible connection between OXIN and the DDX18 and NRP2 genes, although the putative mechanism of interaction of these in relation to OXIN is uncertain [32].

3.2. Prophylaxis. Two different strategies have been advocated to prevent OXIN: (1) a stop-and-go approach with intermittent oxaliplatin dosing and (2) the concurrent use of neuromodulatory agents which include antidepressants, antiepileptics, or calcium and magnesium infusions.

3.2.1. Stop-and-Go Strategy. Given the reversibility of OXIN in the majority of patients, two separate trials have evaluated stopping oxaliplatin after 6 cycles of therapy, and reintroducing the oxaliplatin after a predefined break while continuing the $5 \mathrm{FU}$ backbone of chemotherapy [33-35]. The OPTIMOX1 trial was a European trial involving 620 patients, which compared continuous FOLFOX-4 regimen (oxaliplatin $85 \mathrm{mg} / \mathrm{m}^{2}$ ) to an intermittent FOLFOX-7 regimen (oxaliplatin $130 \mathrm{mg} / \mathrm{m}^{2}$ for 6 cycles with infusional $5 \mathrm{FU} / \mathrm{LV}$ then a complete oxaliplatin treatment break) with maintenance 5 FU/LV (12 cycles) followed by reintroduction of FOLFOX7 (6 cycles) [33]. The incidence of neuropathy was less in the intermittent arm between cycle 7 and 18, but the overall rate of grade 3 neurotoxicity was not significantly different (13\% intermittent FOLFOX-7 versus 19\% FOLFOX-4, $P=0.12$ ). 
Notably, although $60 \%$ of patients in the intermittent arm did not receive further oxaliplatin after their scheduled break from treatment, the response rate, progression-free survival, and overall survival were similar in both arms. The CONcePT trial also compared intermittent to continuous oxaliplatin administration, in a $2 \times 2$ design additionally randomizing patients to either calcium/magnesium infusion or placebo [35]. This trial used modified FOLFOX-7 (oxaliplatin $85 \mathrm{mg} / \mathrm{m}^{2}$ ) and bevacizumab in both arms, but with alternating blocks of 8 cycles of treatment with oxaliplatin with 8 cycles of biweekly $5 \mathrm{FU} / \mathrm{LV} /$ bevacizumab in the intermittent treatment arm. Grade 3 neurotoxicity was significantly reduced in the intermittent oxaliplatin arm versus the continuous oxaliplatin arm (10\% versus $24 \%$ ). Dose delay or dose reduction was significantly less in the intermittent arm compared to the continuous arm ( $8 \%$ versus $22 \%)$. Additionally, the intermittent oxaliplatin arm had better time to treatment failure and progression-free survival than the continuous arm.

While the improvement in neurotoxicity is appealing in the stop-and-go approach use of oxaliplatin, the continuation of the $5 \mathrm{FU} / \mathrm{LV}$ may be important to maintain efficacy relative to continuous oxaliplatin [36]. The OPTIMOX2 trial compared chemotherapy discontinuation after 6 cycles of FOLFOX-7 with maintenance therapy after 6 cycles of FOLFOX-7, as was used in OPTIMOX1. This approach resulted in inferior duration of disease control and inferior survival, and is not recommended [37]. However, it is important to note that this study was terminated early (and thus analyzed as a randomized phase II), and tumor size was required to surpass baseline measurements prior to reintroduction-an approach which is not used commonly in the clinic. The MACRO trial was a large randomized phase III study that evaluated capecitabine and oxaliplatin (XELOX) with bevacizumab for 6 cycles, followed by maintenance XELOX-bevacizumab or single-agent bevacizumab [38]. This study reported a reduction in grade $3 / 4$ neuropathy from $24 \%$ in the continuous XELOX-bevacizumab arm to $7 \%$ in the bevacizumab alone arm, with no difference in PFS, OS between the two arms. Therefore stop-and-go oxaliplatin use is as efficacious as continuous oxaliplatin usage when either a $5 \mathrm{FU} / \mathrm{LV}$ or bevacizumab backbone is used as maintenance, and results in reduced neurotoxicity. The timing for reintroduction of oxaliplatin is uncertain, and the optimum oxaliplatin-based regimen to use with this approach is also unknown.

3.2.2. Calcium and Magnesium. Calcium and magnesium infusions have been tried as prophylactic therapy for OXIN, on the basis that they may bind to oxalate, and reduce its effect on voltage-gated sodium channels $[10,39]$. An encouraging retrospective review [40] of a single institution experience with calcium and magnesium infusions, given before and after oxaliplatin administration, has led to three prospective randomized trials of the strategy. Patients in the CONcePT trial were randomized to either placebo, or $\mathrm{Ca} / \mathrm{Mg}$ infusion (calcium gluconate $1 \mathrm{~g}$, magnesium sulfate $1 \mathrm{~g}$, in $100 \mathrm{~mL}$ of $5 \%$ dextrose in water, half an hour prior and half an hour after oxaliplatin administration). Interim analysis of the study data which suggested a decreased response rate in the $\mathrm{Ca} / \mathrm{Mg}$ arm led to premature closure of the trial [34] after enrolment of only 139 patients. However a subsequent independent review demonstrated that there was no significant difference in response rate or time to treatment failure between the groups. $\mathrm{Ca} / \mathrm{Mg}$ infusion did not lead to a significant reduction in grade $3 / 4$ neurotoxicity either in the continuous oxaliplatin arm $(23 \% \mathrm{Ca} / \mathrm{Mg}$ group versus $24 \%$ placebo $)$ or in the intermittent arm $(11 \% \mathrm{Ca} / \mathrm{Mg}$ group versus $8 \%$ placebo). There was also no difference in the groups between delays and dose reductions. A retrospective review of the effectiveness of $\mathrm{Ca} / \mathrm{Mg}$ infusions on neuropathy from the CAIRO2 trial also reported no substantial benefit in the reduction of grade $3 / 4$ neuropathy [41].

In contrast the double blinded, placebo-controlled N04C7 trial of patients receiving continuous FOLFOX reported significantly lower grade 2 or worse neurotoxicity in the $\mathrm{Ca} / \mathrm{Mg}$ arm (22\% versus $41 \%)$ [18]. In addition, the $\mathrm{Ca} / \mathrm{Mg}$ group had decreased amounts of muscle cramping, but there was no difference in cold sensitivity. The trial was unfortunately closed after only 102 patients were recruited due to concerns regarding the CONcePT trial's early erroneous assessment of inferior response in the $\mathrm{Ca} / \mathrm{Mg}$ arm, leading to lack of statistical power to determine if there was a difference in dose delay and dose reduction between the two groups. Preliminary data, taken from an early interim analysis of 52 patients on the blinded, placebo-controlled Neuroxa trial, is also supportive of $\mathrm{Ca} / \mathrm{Mg}$ infusions [42]. There was a significantly lower frequency of grade $3 / 4$ neurotoxicity in the group receiving $\mathrm{Ca} / \mathrm{Mg}$ infusions (5\% versus $24 \%$ ), and there was no difference in efficacy between the groups.

An explanation for the possible discrepancy between the insignificant outcomes of $\mathrm{Ca} / \mathrm{Mg}$ in CONcePT and CAIRO2 compared to the benefit seen in the N04C7 and NEUROXA trial is the number of initial oxaliplatin cycles patients received. Half the patients in the CONcePT trial received stopand-go therapy with oxaliplatin, and all patients in CAIRO2 had at most 6 cycles of oxaliplatin. These measures by themselves have been shown to reduce neurotoxicity, as demonstrated by the OPTIMOX1 trial [33]. In contrast the N04C7 and Neuroxa trial treated patients with continuous oxaliplatin, suggesting the benefit of $\mathrm{Ca} / \mathrm{Mg}$ infusions are limited to this treatment strategy. However despite the favorable results from the N04C7 and the NEUROXA trial, there are no current data available on the effect of $\mathrm{Ca} / \mathrm{Mg}$ infusions on longer-term OXIN [53], and a subsequent further randomized NCCTG trial has begun enrollment to answer this question.

3.2.3. Pharmacological Approaches. A variety of pharmacological approaches to prevent neurotoxicity have been studied, but none have shown sufficient success to use routinely. Tables 2 and 3 summarizes the trials, their interventions, and results.

Glutathione, a tripeptide amino acid, has been shown to act as an antioxidant and prevent oxaliplatin accumulation in nerves [54, 55]. A small 52-patient randomized trial of intravenous reduced dose glutathione given with oxaliplatin reported that the rate of grade 3 neurotoxicity at 8 weeks was significantly less in the group receiving glutathione $(0 \%$ 
TABLe 2: Prevention of oxaliplatin-induced peripheral neuropathy.

\begin{tabular}{|c|c|c|}
\hline Study reference & Intervention & Results \\
\hline OPTIMOX1 [33] & $\begin{array}{l}\text { Continuous FOLFOX-4 versus } \\
\text { intermittent FOLFOX-7 }\end{array}$ & $\begin{array}{l}\text { No significant reduction in grade } 3 \text { neuropathy in the } \\
\text { intermittent arm }\end{array}$ \\
\hline \multirow{2}{*}{ CONcePT [34] } & $\begin{array}{l}\text { Continuous oxaliplatin versus } \\
\text { intermittent oxaliplatin }\end{array}$ & Reduced grade 3 neuropathy in the intermittent arm \\
\hline & $\mathrm{Ca} / \mathrm{Mg}$ versus placebo & No reduction in grade $3 / 4$ neuropathy in $\mathrm{Ca} / \mathrm{Mg}$ group \\
\hline Gamelin et al. 2004 [40] & $\begin{array}{l}\mathrm{Ca} \text { and } \mathrm{Mg} \text { versus historic } \\
\text { control }\end{array}$ & Reduced grade 3 neuropathy in $\mathrm{Ca} / \mathrm{Mg}$ group \\
\hline CAIRO2 trial $[41]$ & $\begin{array}{l}\mathrm{Ca} / \mathrm{Mg} \text { versus no prevention } \\
\text { treatment }\end{array}$ & No reduction in grade $3 / 4$ neuropathy in $\mathrm{Ca} / \mathrm{Mg}$ group \\
\hline N04C7 trial [18] & $\mathrm{Ca} / \mathrm{Mg}$ versus placebo & Reduced grade 2 or worse neuropathy in $\mathrm{Ca} / \mathrm{Mg}$ group \\
\hline $\begin{array}{l}\text { Neuroxa trial (ongoing) } \\
{[42]}\end{array}$ & $\begin{array}{l}\mathrm{Ca} / \mathrm{Mg} \text { versus no prevention } \\
\text { treatment }\end{array}$ & Reduced grade 3 neuropathy in $\mathrm{Ca} / \mathrm{Mg}$ group \\
\hline Cascinu et al. 2002 [43] & Glutathione versus placebo & Reduced grade 3 neuropathy with glutathione \\
\hline Lin et al. $2006[44]$ & $\mathrm{N}$-acetylcysteine versus placebo & Reduced grades 2-4 neuropathy with $\mathrm{N}$-acetylcysteine \\
\hline Wang et al. 2007 [45] & Glutamine versus no treatment & Reduced grade 3 neuropathy with glutamine \\
\hline Lu et al. 2008 [46] & Amifostine versus glutamine & Reduced grades 1-2 and 3-4 in amifostine group \\
\hline Guo et al. 2011 [47] & Oral lipoic acid versus placebo & No statistical difference in treatment groups \\
\hline Von Delius et al. 2007 [48] & $\begin{array}{l}\text { Carbamazepine versus no } \\
\text { prevention treatment }\end{array}$ & No statistical difference in treatment groups \\
\hline Argyriou et al. 2006 [49] & $\begin{array}{l}\text { Oxcarbazepine versus no } \\
\text { prevention treatment }\end{array}$ & $\begin{array}{l}\text { Reduction in incidence of neuropathy in oxcarbazepine } \\
\text { group }\end{array}$ \\
\hline Mitchell et al. 2006 [50] & $\begin{array}{l}\text { Gabapentin versus no prevention } \\
\text { treatment }\end{array}$ & No reduction in neuropathy \\
\hline Durand et al. 2003 [51] & Venlafaxine versus placebo & Reduced grade 3 neuropathy \\
\hline Cassidy et al. 2008 [16] & Xaliproden versus placebo & $\begin{array}{l}\text { Reduced grade } 3 \text { during treatment, but no difference } \\
\text { after finishing treatment }\end{array}$ \\
\hline
\end{tabular}

TABLE 3: Treatment of oxaliplatin-induced peripheral neuropathy.

\begin{tabular}{lll}
\hline Study & Intervention & Results \\
\hline Durand et al. 2003 [51] & $\begin{array}{l}\text { Venlafaxine versus } \\
\text { placebo }\end{array}$ & $\begin{array}{l}\text { Reduced grade 3 } \\
\text { neuropathy }\end{array}$ \\
Rao et al. 2008 [52] & $\begin{array}{l}\text { Lamotrigine versus } \\
\text { placebo }\end{array}$ & $\begin{array}{l}\text { No reduction in } \\
\text { neuropathy }\end{array}$ \\
\hline
\end{tabular}

versus 26\%) [43]. There was no difference in chemotherapy response. N-acetylcysteine, which increases glutathione blood concentrations, showed promising benefit in preventing OXIN in a small 14-patient study [44]. Glutamine, another amino acid, has shown promising preventative qualities in a small randomized trial of oral supplementation, but larger confirmatory trials are required [45]. The free radical scavenger amifostine was more effective than glutamine in preventing neurotoxicity when given subcutaneously before oxaliplatin-based chemotherapy [46]. More recently, lipoic acid, an antioxidant, was shown to be no better than placebo in preventing platinum-induced neuropathy in a randomized trial of giving the drug orally during chemotherapy [47].

Carbamazepine, a widely used antiepileptic drug that blocks sodium channels, has also been tried as a preventative measure. However, the drug has a wide range of side effects and low therapeutic index, and a randomized trial of the strategy was ineffective [48]. Gabapentin was also ineffective when tried as a preventative measure in a randomised trial [50]. Oxcarbazepine, an analogue of carbamazepine, was effective in a small randomized trial in preventing OXIN [49], but larger confirmatory trials are required.

Xaliproden is an oral drug that acts through the 5HT1 serotonin receptor and has neurotrophic effects [56]. A large randomized trial of xaliproden with 649 patients receiving FOLFOX-4 chemotherapy reported reduced grade 3 neuropathy in patients taking xaliproden (11\% versus $17 \%)$, but there was no difference in the percentage of patients with complete recovery after finishing treatment with oxaliplatin (49 versus 47 percent), and the use of the drug for this indication has been abandoned [57].

\section{Treatment}

There are few comparative studies to guide clinicians regarding appropriate treatment of established acute or chronic OXIN. Venlafaxine, an antidepressant that is a serotonin and norepinephrine reuptake inhibitor, may be appropriate for the treatment of acute OXIN $[51,58]$. A randomized trial of venlafaxine in patients with acute OXIN receiving FOLFOX chemotherapy for adjuvant or palliative treatment of colon cancer demonstrated a reduction in the proportion of patients suffering from acute OXIN from $31.3 \%$ in the placebo 
arm versus $5.3 \%$ in the venlafaxine arm $(P=0.03)$ [58]. Although the trial was small with 54 patients, it also demonstrated in a secondary endpoint that venlafaxine was effective in reducing the incidence of chronic OXIN that was grade 3 or worse from $33 \%$ in the placebo arm to $0 \%$ in the venlafaxine arm, suggestive that venlafaxine therapy may also be useful as a preventative measure. Amitriptyline use resulted in a nonsignificant trend to improvement in sensory neuropathy in a small, 44-patient randomized trial of cancer patients with chemotherapy-induced neuropathy, of whom 11 patients had oxaliplatin-induced pain [59]. However, a negative randomised trial suggests lamotrigine is ineffective as treatment for chemotherapy-induced neuropathy [52]. Based on individual case reports and small nonrandomized series, other potential therapeutic options for patients, once large confirmatory studies are done, include gabapentin [60] and pregabalin $[60,61]$.

\section{Conclusion}

OXIN causes significant morbidity and is often the dose-limited factor in treatment of advanced colon cancer. Significant advancement has been made to understand the acute and chronic phases of OXIN, but further research is necessary to develop rational therapeutic options. The current literature in prevention of OXIN is inadequate to guide clinical decision making. Larger future studies are needed to further elucidate the most effective strategies of prevention and treatment of OXIN.

\section{References}

[1] T. Andre, C. Boni, L. Mounedji-Boudiaf et al., "Oxaliplatin, fluorouracil, and leucovorin as adjuvant treatment for colon cancer," New England Journal of Medicine, vol. 350, no. 23, pp. 2343-2351, 2004.

[2] H. J. Schmoll, T. Cartwright, J. Tabernero et al., "Phase III trial of capecitabine plus oxaliplatin as adjuvant therapy for stage III colon cancer: a planned safety analysis in 1,864 patients," Journal of Clinical Oncology, vol. 25, no. 1, pp. 102-109, 2007.

[3] G. Masi, E. Vasile, F. Loupakis et al., "Randomized trial of two induction chemotherapy regimens in metastatic colorectal cancer: an updated analysis," Journal of the National Cancer Institute, vol. 103, no. 1, pp. 21-30, 2011.

[4] T. Alcindor and N. Beauger, "Oxaliplatin: a review in the era of molecularly targeted therapy," Current Oncology, vol. 18, no. 1, pp. 18-25, 2011.

[5] S. G. Chaney, E. Raymond, S. Faivre, and J. M. Woynarowski, "Oxaliplatin: mechanism of action and antineoplastic activity," Seminars in Oncology, vol. 25, no. 2, pp. 4-12, 1998.

[6] J. T. Hartmann and H. P. Lipp, "Toxicity of platinum compounds," Expert Opinion on Pharmacotherapy, vol. 4, no. 6, pp. 889-901, 2003.

[7] R. J. Cersosimo, "Oxaliplatin-associated neuropathy: a review," Annals of Pharmacotherapy, vol. 39, no. 1, pp. 128$135,2005$.

[8] A. A. Argyriou, P. Polychronopoulos, G. Iconomou, E. Chroni, and H. P. Kalofonos, "A review on oxaliplatin-induced peripheral nerve damage," Cancer Treatment Reviews, vol. 34, no. 4, pp. 368-377, 2008.
[9] H. Adelsberger, S. Quasthoff, J. Grosskreutz, A. Lepier, F. Eckel, and C. Lersch, "The chemotherapeutic oxaliplatin alters voltage-gated $\mathrm{Na}(+)$ channel kinetics on rat sensory neurons," European Journal of Pharmacology, vol. 406, no. 1, pp. 25-32, 2000.

[10] F. Grolleau, L. Gamelin, M. Boisdron-Celle, B. Lapied, M. Pelhate, and E. Gamelin, "A possible explanation for a neurotoxic effect of the anticancer agent oxaliplatin on neuronal voltagegated sodium channels," Journal of Neurophysiology, vol. 85, no. 5, pp. 2293-2297, 2001.

[11] L. Gamelin, O. Capitain, A. Morel et al., "Predictive factors of oxaliplatin neurotoxicity: the involvement of the oxalate outcome pathway," Clinical Cancer Research, vol. 13, no. 21, pp. 6359-6368, 2007.

[12] A. Grothey, "Clinical management of oxaliplatin-associated neurotoxicity," Clinical Colorectal Cancer, vol. 5, no. 1, supplement 1, pp. S38-S46, 2005.

[13] Services, U.S.D.o.H.a.H., National Cancer Institute Common Terminology Criteria for Adverse Events (CTCAE) Version 4.03. 2010.

[14] D. R. Cornblath, V. Chaudhry, K. Carter et al., "Total neuropathy score: validation and reliability study," Neurology, vol. 53, no. 8, pp. 1660-1664, 1999.

[15] G. Cavaletti, G. Bogliun, L. Marzorati et al., "Grading of chemotherapy-induced peripheral neurotoxicity using the Total Neuropathy Scale," Neurology, vol. 61, no. 9, pp. 12971300, 2003.

[16] J. Cassidy, S. Clarke, E. Díaz-Rubio et al., "Randomized phase III study of capecitabine plus oxaliplatin compared with fluorouracil/folinic acid plus oxaliplatin as first-line therapy for metastatic colorectal cancer," Journal of Clinical Oncology, vol. 26, no. 12, pp. 2006-2012, 2008.

[17] A. Falcone, S. Ricci, I. Brunetti et al., "Phase III trial of infusional fluorouracil, leucovorin, oxaliplatin, and irinotecan (FOLFOXIRI) compared with infusional fluorouracil, leucovorin, and irinotecan (FOLFIRI) as first-line treatment for metastatic colorectal cancer: the gruppo oncologico nord ovest," Journal of Clinical Oncology, vol. 25, no. 13, pp. 16701676, 2007.

[18] A. Grothey, D. A. Nikcevich, J. A. Sloan et al., "Intravenous calcium and magnesium for oxaliplatin-induced sensory neurotoxicity in adjuvant colon cancer: NCCTG N04C7," Journal of Clinical Oncology, vol. 29, no. 4, pp. 421-427, 2011.

[19] C. J. Allegra, G. Yothers, M. J. O’Connell et al., "Initial safety report of NSABP C-08: a randomized phase III study of modified FOLFOX6 with or without bevacizumab for the adjuvant treatment of patients with stage II or III colon cancer," Journal of Clinical Oncology, vol. 27, no. 20, pp. 33853390, 2009.

[20] A. De Gramont, A. Figer, M. Seymour et al., "Leucovorin and fluorouracil with or without oxaliplatin as first-line treatment in advanced colorectal cancer," Journal of Clinical Oncology, vol. 18, no. 16, pp. 2938-2947, 2000.

[21] S. R. Land, J. A. Kopec, R. S. Cecchini et al., "Neurotoxicity from oxaliplatin combined with weekly bolus fluorouracil and leucovorin as surgical adjuvant chemotherapy for stage II and III colon cancer: NSABP C-07," Journal of Clinical Oncology, vol. 25, no. 16, pp. 2205-2211, 2007.

[22] A. A. Argyriou, P. Polychronopoulos, G. Iconomou et al., "Incidence and characteristics of peripheral neuropathy during oxaliplatin-based chemotherapy for metastatic colon cancer," Acta Oncologica, vol. 46, no. 8, pp. 1131-1137, 2007. 
[23] S. B. Park, C. S.Y. Lin, A. V. Krishnan, D. Goldstein, M. L. Friedlander, and M. C. Kiernan, "Long-term neuropathy after oxaliplatin treatment: challenging the dictum of reversibility," Oncologist, vol. 16, no. 5, pp. 708-716, 2011.

[24] R. K. Ramanathan, M. L. Rothenberg, A. de Gramont et al., "Incidence and evolution of oxaliplatin-induced eripheral sensory neuropathy in diabetic patients with colorectal cancer: a pooled analysis of three phase III studies," Annals of Oncology, vol. 21, no. 4, pp. 754-758, 2009.

[25] R. M. Goldberg, I. Tabah-Fisch, H. Bleiberg et al., "Pooled analysis of safety and efficacy of oxaliplatin plus fluorouracil/leucovorin administered bimonthly in elderly patients with colorectal cancer," Journal of Clinical Oncology, vol. 24, no. 25, pp. 4085-4091, 2006.

[26] V. Adler, Z. Yin, S. Y. Fuchs et al., "Regulation of JNK signaling by GSTp,” EMBO Journal, vol. 18, no. 5, pp. 1321-1334, 1999.

[27] R. Elsby, N. R. Kitteringham, C. E. Goldring et al., "Increased constitutive c-Jun $\mathrm{N}$-terminal kinase signaling in mice lacking glutathione S-transferase Pi," Journal of Biological Chemistry, vol. 278, no. 25, pp. 22243-22249, 2003.

[28] C. J. Henderson, A. W. McLaren, G. J. Moffat, E. J. Bacon, and C. R. Wolf, "Pi-class glutathione S-transferase: regulation and function," Chemico-Biological Interactions, vol. 111-112, pp. 69-82, 1998.

[29] T. Lecomte, B. Landi, P. Beaune, P. Laurent-Puig, and M. A. Loriot, "Glutathione S-transferase P1 polymorphism (Ile105Val) predicts cumulative neuropathy in patients receiving oxaliplatin-based chemotherapy," Clinical Cancer Research, vol. 12, no. 10, pp. 3050-3056, 2006.

[30] M. Kanai, A. Yoshioka, S. Tanaka et al., "Associations between glutathione S-transferase $\pi$ Ile105Val and glyoxylate aminotransferase Pro11Leu and Ile340Met polymorphisms and early-onset oxaliplatin-induced neuropathy," Cancer Epidemiology, vol. 34, no. 2, pp. 189-193, 2010.

[31] A. G. Antonacopoulou, A. A. Argyriou, C. D. Scopa et al., "Integrin beta-3 L33P: a new insight into the pathogenesis of chronic oxaliplatin-induced peripheral neuropathy?" European Journal of Neurology, vol. 17, no. 7, pp. 963-968, 2010.

[32] S. Lee, H. Won, E. Son et al., "Genetic polymorphism associated with chronic neurotoxicity and recurrence in curatively-resected colon cancer patients receiving oxaliplatinbased adjuvant chemotherapy," Journal of Clinical Oncology, vol. 28, no. 15, supplement, p. 3583, ASCO Meeting Abstracts, 2010.

[33] C. Tournigand, A. Cervantes, A. Figer et al., "OPTIMOX1: a randomized study of FOLFOX4 or FOLFOX7 with oxaliplatin in a stop-and-go fashion in advanced colorectal cancer-a GERCOR study," Journal of Clinical Oncology, vol. 24, no. 3, pp. 394-400, 2006.

[34] H. S. Hochster, A. Grothey, and B. H. Childs, "Use of calcium and magnesium salts to reduce oxaliplatin-related neurotoxicity," Journal of Clinical Oncology, vol. 25, no. 25, pp. 4028-4029, 2007.

[35] A. Grothey, L. L. Hart, K. M. Rowland et al., "Intermittent oxaliplatin (oxali) administration and time-to-treatmentfailure (TTF) in metastatic colorectal cancer (mCRC): final results of the phase III CONcePT trial," Journal of Clinical Oncology, vol. 26, no. 15, supplement, p. 4010, ASCO Meeting Abstracts, 2008.

[36] I. Chau and D. Cunningham, "Treatment in advanced colorectal cancer: what, when and how?" British Journal of Cancer, vol. 100, no. 11, pp. 1704-1719, 2009.
[37] B. Chibaudel, F. Maindrault-Goebel, G. Lledo et al., "Can chemotherapy be discontinued in unresectable metastatic colorectal cancer? The GERCOR OPTIMOX2 study," Journal of Clinical Oncology, vol. 27, no. 34, pp. 5727-5733, 2009.

[38] J. Tabernero, E. Aranda, A. Gomez et al., "Phase III study of first-line XELOX plus bevacizumab (BEV) for 6 cycles followed by XELOX plus BEV or single-agent (s/a) BEV as maintenance therapy in patients (pts) with metastatic colorectal cancer (mCRC): the MACRO trial (Spanish Cooperative Group for the Treatment of Digestive Tumors [TTD])," Journal of Clinical Oncology, vol. 28, no. 15, supplement, p. 3501, ASCO Meeting Abstracts, 2010.

[39] E. Gamelin, L. Gamelin, L. Bossi, and S. Quasthoff, "Clinical aspects and molecular basis of oxaliplatin neurotoxicity: current management and development of preventive measures," Seminars in Oncology, vol. 29, no. 5, supplement 15, pp. 2133, 2002.

[40] L. Gamelin, M. Boisdron-Celle, R. Delva et al., "Prevention of oxaliplatin-related neurotoxicity by calcium and magnesium infusions: a retrospective study of 161 patients receiving oxaliplatin combined with 5-fluorouracil and leucovorin for advanced colorectal cancer," Clinical Cancer Research, vol. 10, no. 12, pp. 4055-4061, 2004.

[41] N. Knijn, J. Tol, M. Koopman et al., "The effect of prophylactic calcium and magnesium infusions on the incidence of neurotoxicity and clinical outcome of oxaliplatin-based systemic treatment in advanced colorectal cancer patients," European Journal of Cancer, vol. 47, no. 3, pp. 369-374, 2010.

[42] L. Gamelin, M. Boisdron-Celle, A. Morel et al., "Oxaliplatinrelated neurotoxicity: interest of calcium-magnesium infusion and no impact on its efficacy," Journal of Clinical Oncology, vol. 26, no. 7, pp. 1188-1189, 2008.

[43] S. Cascinu, V. Catalano, L. Cordella et al., "Neuroprotective effect of reduced glutathione on oxaliplatin-based chemotherapy in advanced colorectal cancer: a randomized, doubleblind, placebo-controlled trial," Journal of Clinical Oncology, vol. 20, no. 16, pp. 3478-3483, 2002.

[44] P. C. Lin, M. Y. Lee, W. S. Wang et al., "N-acetylcysteine has neuroprotective effects against oxaliplatin-based adjuvant chemotherapy in colon cancer patients: preliminary data," Supportive Care in Cancer, vol. 14, no. 5, pp. 484-487, 2006.

[45] W. S. Wang, J. K. Lin, T. C. Lin et al., "Oral glutamine is effective for preventing oxaliplatin-induced neuropathy in colorectal cancer patients," Oncologist, vol. 12 , no. 3, pp. 312319, 2007.

[46] P. Lu, Q. X. Fan, L. X. Wang, X. Wang, H. Zong, and R. L. Wang, "Prophylactic effect of amifostine on oxaliplatinrelated neurotoxicity in patients with digestive tract tumors," Ai Zheng, vol. 27, no. 10, pp. 1117-1120, 2008.

[47] Y. Guo, J. L. Palmer, A. Forman et al., "A randomized, double-blinded, placebo-controlled trial of oral alpha lipoic acid to prevent platinum-induced polyneuropathy," Journal of Clinical Oncology, vol. 29, no. 15, supplement, p. 9010, ASCO Meeting Abstracts, 2011.

[48] S. von Delius, F. Eckel, S. Wagenpfeil et al., "Carbamazepine for prevention of oxaliplatin-related neurotoxicity in patients with advanced colorectal cancer: final results of a randomised, controlled, multicenter phase II study," Investigational New Drugs, vol. 25, no. 2, pp. 173-180, 2007.

[49] A. A. Argyriou, E. Chroni, P. Polychronopoulos et al., "Efficacy of oxcarbazepine for prophylaxis against cumulative oxaliplatin-induced neuropathy," Neurology, vol. 67, no. 12, pp. 2253-2255, 2006. 
[50] P. L. Mitchell, D. Goldstein, M. Michael et al., "Addition of gabapentin to a modified FOLFOX regimen does not reduce oxaliplatin-induced neurotoxicity," Clinical Colorectal Cancer, vol. 6, no. 2, pp. 146-151, 2006.

[51] J. P. Durand, C. Brezault, and F. Goldwasser, "Protection against oxaliplatin acute neurosensory toxicity by venlafaxine," Anti-Cancer Drugs, vol. 14, no. 6, pp. 423-425, 2003.

[52] R. D. Rao, P. J. Flynn, J. A. Sloan et al., "Efficacy of lamotrigine in the management of chemotherapy-induced peripheral neuropathy: a phase 3 randomized, double-blind, placebocontrolled trial, N01C3," Cancer, vol. 112, no. 12, pp. 28022808, 2008.

[53] S. B. Park, D. Goldstein, C. S.-Y. Lin, A. V. Krishnan, M. L. Friedlander, and M. C. Kiernan, "Neuroprotection for oxaliplatin-induced neurotoxicity: what happened to objective assessment?" Journal of Clinical Oncology, vol. 29, no. 18, pp. e553-e554, 2011.

[54] A. Reynolds, C. Laurie, R. Lee Mosley, and H. E. Gendelman, "Oxidative stress and the pathogenesis of neurodegenerative disorders," International Review of Neurobiology, vol. 82, pp. 297-325, 2007.

[55] J. Holmes, J. Stanko, M. Varchenko et al., "Comparative neurotoxicity of oxaliplatin, cisplatin, and ormaplatin in a wistar rat model," Toxicological Sciences, vol. 46, no. 2, pp. 342351, 1998.

[56] A. Appert-Collin, F. H. T. Duong, P. Passilly Degrace, J. M. Warter, P. Poindron, and J. P. Gies, "MAPK activation via 5-hydroxytryptamine $1 \mathrm{~A}$ receptor is involved in the neuroprotective effects of xaliproden," International Journal of Immunopathology and Pharmacology, vol. 18, no. 1, pp. 21-31, 2005.

[57] J. Cassidy, G. A. Bjarnason, T. Hickish et al., "Randomized double blind (DB) placebo (Plcb) controlled phase III study assessing the efficacy of xaliproden $(\mathrm{X})$ in reducing the cumulative peripheral sensory neuropathy (PSN) induced by the oxaliplatin (Ox) and 5-FU/LV combination (FOLFOX4) in first-line treatment of patients (pts) with metastatic colorectal cancer (MCRC)," Journal of Clinical Oncology, vol. 24, no. 18, supplement, p. 3507, 2006.

[58] J. P. Durand, G. Deplanque, V. Montheil et al., "Efficacy of venlafaxine for the prevention and relief of oxaliplatininduced acute neurotoxicity: results of EFFOX, a randomized, double-blind, placebo-controlled phase III trial," Annals of Oncology. In press.

[59] A. L. Kautio, M. Haanpää, T. Saarto, and E. Kalso, "Amitriptyline in the Treatment of Chemotherapy-Induced Neuropathic Symptoms," Journal of Pain and Symptom Management, vol. 35, no. 1, pp. 31-39, 2008.

[60] G. Mariani, O. Garonne, and C. Granetto, "Oxaliplatin induced neuropathy: could gabapentin be the answer?" Journal of Clinical Oncology, vol. 19, no. 19, supplement, p. 2937, ASCO Meeting Abstracts, 2000.

[61] M. W. Saif and S. Hashmi, "Successful amelioration of oxaliplatin-induced hyperexcitability syndrome with the antiepileptic pregabalin in a patient with pancreatic cancer," Cancer Chemotherapy and Pharmacology, vol. 61, no. 3, pp. 349-354, 2008. 


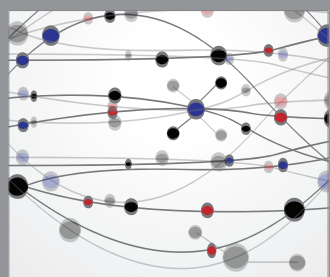

The Scientific World Journal
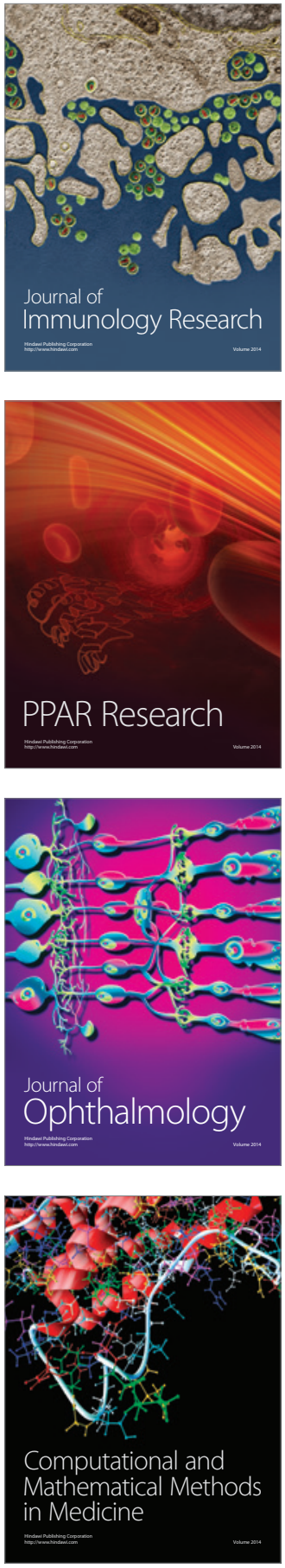

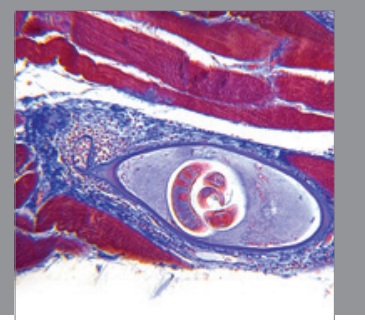

Gastroenterology

Research and Practice
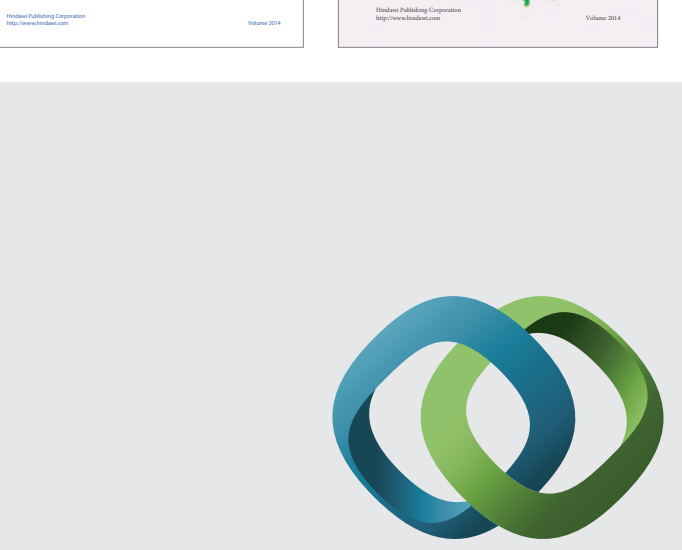

\section{Hindawi}

Submit your manuscripts at

http://www.hindawi.com
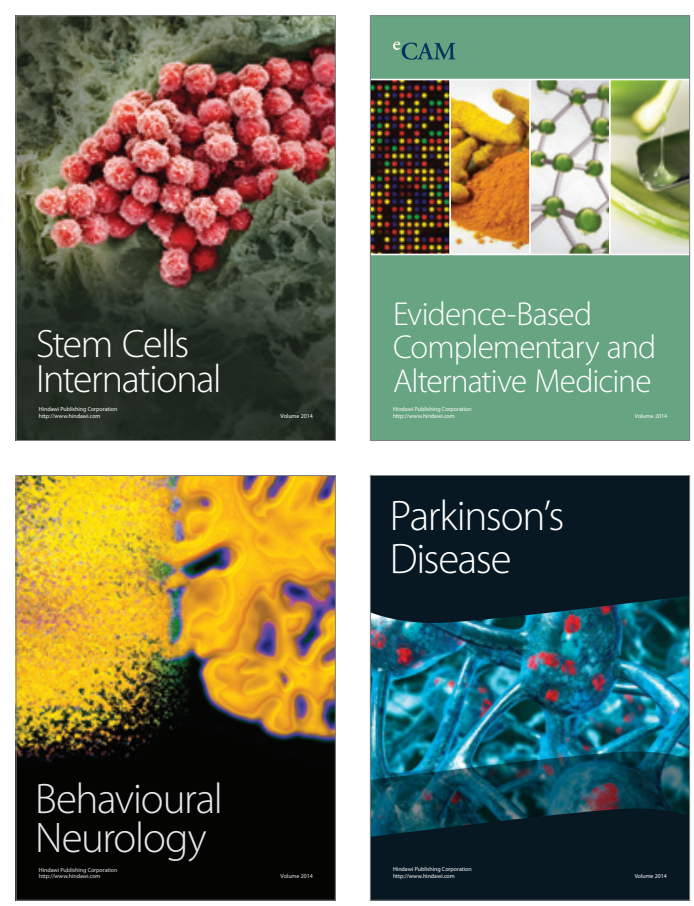

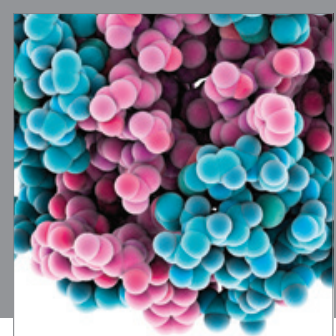

Journal of
Diabetes Research

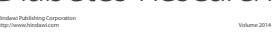

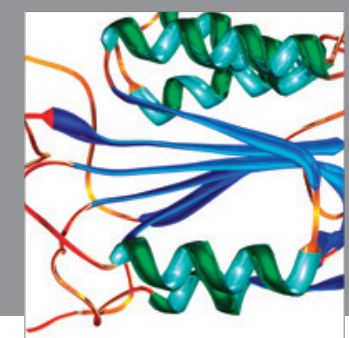

Disease Markers
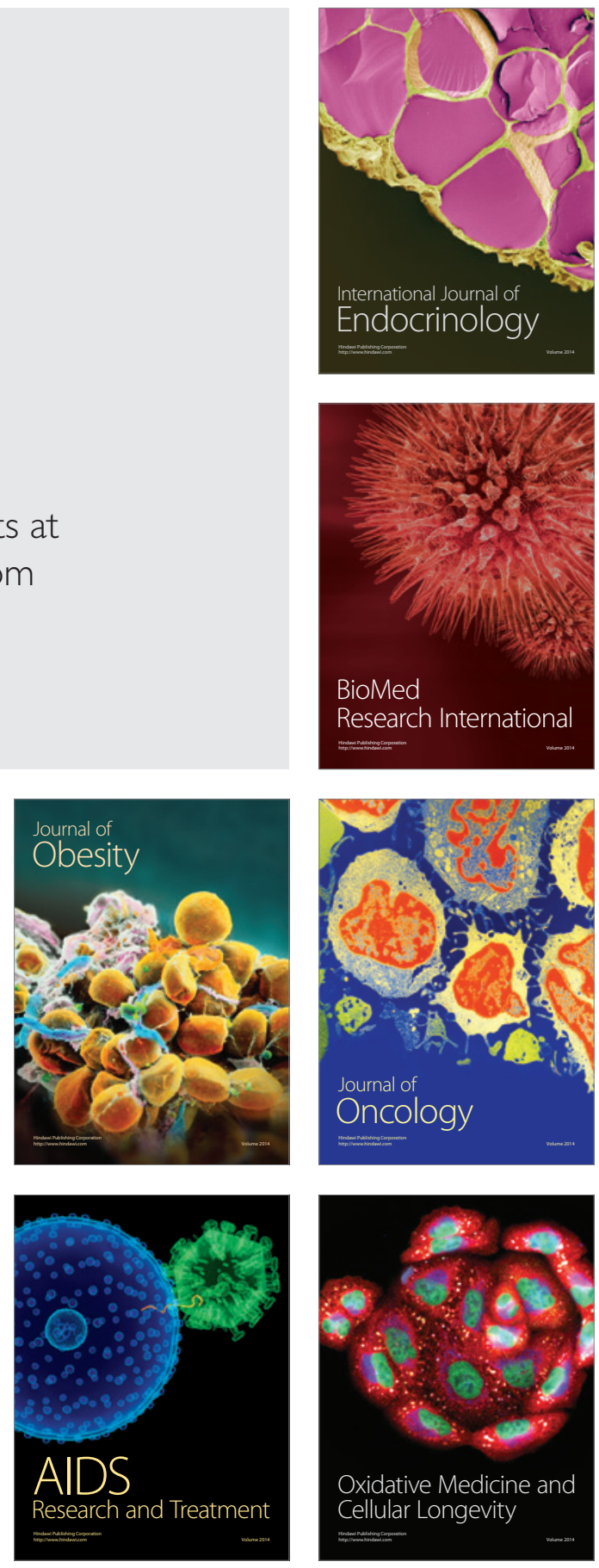